\title{
LA MINERÍA Y EL DESARROLLO INSOSTENIBLE. El estudio de caso en San Juan, Argentina
}

\author{
Margarita Moscheni ${ }^{\mathrm{a}}$
}

Fecha de recepción: 9 de febrero de 2018. Fecha de aceptación: 31 de agosto de 2018.

http://dx.doi.org/10.22201/iiec.20078951e.2019.196.64823

Resumen. "La minería es el motor principal del desarrollo", reza uno de los principales argumentos a favor de esta actividad. Este trabajo es producto de una investigación de tipo interpretativo y comprensivo, que aspira a verificar el slogan mencionado, tomando como caso la minería extractiva en San Juan, provincia ubicada en el centro-oeste de Argentina. Entre los principales resultados obtenidos está que la alta inversión extranjera en minería no es sinónimo de desarrollo, sino por el contrario, genera un crecimiento concentrado, excluyente e insostenible, vulnerando el aparato comercial externo, desplazando las producciones tradicionales y generando un proceso de conflictos socioambientales y de daños ecológicos irreversibles.

Palabras clave: minería; provincia de San Juan; inversión extranjera; exportaciones; contaminación ambiental; daños ecológicos.

Clasificación JEL: L71, L72, R11, Q51, Q56.

\section{A Case Study in Mining and Unsustainable Development: San Juan, Argentina}

\begin{abstract}
Mining is the main engine of development", is one of the most commonly used arguments in support of the activity. This paper is the product of comprehensive interpretive research, which aims to test this hypothesis, using extractive mining in San Juan, a province in the center-west of Argentina, as a case study. One of the key findings of this study is that high foreign investment in mining is not synonymous with development. To the contrary, mining creates growth which is concentrated, exclusive and unsustainable, and which undermines external commercial apparatus, displaces traditional modes of production and triggers a process of socio-environmental conflicts, causing irreversible ecological damage.
\end{abstract}

Key Words: Mining; San Juan province; foreign investment; exports; environmental pollution; ecological damage.

\footnotetext{
${ }^{a}$ Consejo Nacional de Investigaciones Científicas y Técnicas (CONICET)-Universidad Nacional San Juan, Argentina. Correo electrónico: margarita.moscheni@gmail.com
} 


\section{INTRODUCCIÓN}

El objetivo de este trabajo es describir las características del desarrollo que imprime la actividad minera extractiva, aportando evidencia de que la misma está lejos de ser el "motor principal del desarrollo", tal como lo plantean los slogans más importantes de las relaciones de fuerza dominantes. El periodo temporal de estudio fue 2003-2017, por ser el primer año de inicio de la construcción de los campos mineros más importantes.

En primer término se presentan algunas categorías para el análisis, tales como qué se entiende por desarrollo sostenible, así como los principales aportes de la sostenibilidad débil y fuerte. En segundo término, se describen los proyectos extractivistas más importantes que operan en la provincia de San Juan. En tercer término, se analiza la incidencia de la minería tanto en materia medioambiental como en algunas variables productivas. Por último, se presentan las conclusiones.

\section{ALGUNOS ASPECTOS CONCEPTUALES}

\section{Desarrollo sostenible}

Las miradas teóricas sobre la definición de desarrollo sostenible no son homogéneas, no hay una definición establecida y acordada, y su conceptualización se encuentra en constantes modificaciones, dados los distintos aportes transdiciplinares y posturas epistemológicas. En este trabajo se entenderá que el desarrollo sostenible debe reunir como mínimo las siguientes características:

1) El crecimiento económico debe preservar las dimensiones ambientales, sociales, culturales e históricas de un determinado espacio;

2) La equidad intergeneracional es fundamental, pues no es posible satisfacer el bienestar humano presente a costa de las generaciones futuras, ni olvidarse del respeto de lo heredado por generaciones anteriores;

3) El Estado debe tener un papel de intervención importante que garantice los ítems anteriores y controle las explotaciones;

4) La riqueza económica no es suficiente para el bienestar humano, hay recursos vitales básicos más importantes antes que ésta, tales como el agua o el aire;

5) A nivel local, el desarrollo sostenible debe tener como consecuencia la transformación estructural del territorio, de manera tal que se mejoren las condiciones de hábitat materiales e inmateriales en las poblaciones locales; 
6) A nivel global, las definiciones y las prácticas en torno al desarrollo sostenible deben ser las mismas, tanto para países desarrollados, como para los que no lo son.

Dependiendo del desarrollo y la transformación que provoque en el territorio, la sostenibilidad puede adquirir distintas formas: débil o fuerte.

\section{Sostenibilidad débil}

Predomina una mirada positivista que enfatiza en el predominio tecnocrático: la tecnología como un factor clave posible de reemplazar cualquier capital limitado o destruido. En efecto, esta teoría entiende que lo importante no es el capital en sí mismo, sea natural o artificial, sino la conservación del stock global del mismo (Solow, 1991). Por lo tanto, cualquier destrucción de recursos naturales agotables puede ser compensada con una nueva innovación tecnológica, producto de nuevas inversiones.

Esta mirada teórica se enmarca dentro de las teorías del crecimiento económico y la economía de mercado. Será siempre lo más importante, la base para la conservación de los recursos naturales, aunque en su desarrollo implique necesariamente la pérdida de ellos. Mass-Colell (p. 207 citado en Pañeda, 1994, p. 206) se pronuncia en una conferencia en este sentido, elogiando dicho crecimiento: "es por nuestra riqueza, que no por nuestra pobreza, como salvaremos la naturaleza”. Él mismo afirma que: "mientras la tecnología evolucione puede haber una sustitución ilimitada de los recursos" (Más-Colell, 1994, citado en López Pardo, 2012, p. 39).

La fe en el reemplazo de un recurso (natural) por otro (artificial vía tecnología) es compartida por muchos autores en este enfoque. Esto es posible básicamente porque se supone que el dinero obtenido por la producción-que destruiría el ecosistema- retornaría a su conservación a través de inversiones que supondrían un aumento en el stock del capital tecnológico. De esta manera, la sustitución del capital ya destruido advierte que las acciones derivadas de una propuesta de sostenibilidad débil intervienen sobre las consecuencias y no sobre las causas (sino enfatizaría en la creación de tecnología que preserve el medio ambiente en el proceso mismo de producción que genera crecimiento).

Kappor (2001), citado en López Pardo (2012, p. 204) enumera algunas de las variables más importantes que revisten las políticas de gestión ambiental diseñadas en el marco de la sostenibilidad débil: 
- Excluyen el entorno social (sólo abordan el natural), dejando a la población en riesgo fuera de las decisiones importantes que afectan su hábitat;

- Se prioriza el crecimiento económico y la privatización de los recursos naturales;

- Hay una despolitización de la cuestión ambiental (citado en López Pardo, 2012, p. 204).

O’Riordan (1996), citado en López Pardo (2012, p. 275) complementa con las siguientes variables:

- Hay una escasa intención de integración de las políticas;

- Baja concientización social;

- Poca cobertura mediática (citado en López Pardo, 2012, p. 275).

La participación social que facilitan en los procesos de gobernanza es reemplazada por las decisiones de inversión que abogan por un crecimiento económico, fuente del bienestar humano (enfoque neoclásico). En el plano de las políticas públicas la evaluación se realiza teniendo bajo criterio costobeneficio ( $\mathrm{ACB}$ ), es decir, la alternativa que implique un menor costo y un mayor beneficio.

Falconí pone en la pista del origen teórico de la sostenibilidad débil, por un lado, las propuestas de Lewis Gray de 1913-1914 y Harold Hotelling (1999), citado en Falconí (2002, p. 37) que afirman que:

La elección óptima depende de la comparación entre la ganancia neta (precio de mercado menos costo marginal de extracción) producida por vender el recurso natural e invertirlo a la tasa de interés de mercado y, la ganancia obtenida por mantener el recurso en el subsuelo para venderlo en el futuro.

Por otro lado, encuentra su origen en los modelos neoclásicos del crecimiento económico de los ańos setenta (Falconí, 2002, p. 38) basados en recursos agotables, entre los que se destacan pensadores como Solow, Stiglitz o Hartwick.

En primer término, Solow (1974) aspira a identificar las condiciones de crecimiento de una economía en un contexto de recursos naturales que se agotan, entendiendo que las generaciones anteriores pueden recurrir a un grupo de recursos limitados al agregar stock de capital reproducible: 
One of the objectives of Solow (1974) was to look at the conditions that would allow an economy to grow forever under the presence of limited natural resources. According to his model, considering that some resource could be available only in limited amount did not necessarily change the possibility for output to grow indefinitely. Furthermore, he stated that the earlier generations could always draw on the finite pool of resources as long as they added to the stock of reproducible capital (Cabeza Gutés, 1996, p. 148).

En segundo término, Stiglitz (citado en Cabeza Gutés, 1996, p. 149) se enfoca en el papel de la tecnología como elemento clave para la sustitución del capital natural por el artificial. Al igual que Solow se basa en la función de producción Cobb-Douglas, según la cual el costo del capital hecho por el hombre es mayor que la participación del capital natural.

La capacidad de sustitución recibió críticas estructurales sobre las restricciones que presenta la tecnología para reemplazar ciertos procesos naturales, de esta manera, citando a Daly (1992), Leal afirma:

El principio de sustitución resulta distractivo e insuficiente frente a los problemas ambientales globales como la contaminación, el calentamiento global o el agujero en la capa de ozono. Sin importar los avances técnicos o la inversión realizada no se ha podido reemplazar la capacidad autodepuradora y recicladora de la naturaleza, no se ha podido detener el calentamiento global, ni solucionar la filtración de ración ultravioleta $(2008$, p. 7$)$.

En tercer término, otro aporte interesante que señala Cabeza Gutés es el de la regla de ahorro-inversión de Hartwick "to have a stream of constant level of consumption per capita to infinity, society should invest all the current returns obtained from the utilization of the stock of exhaustible resources" (citado en Cabeza Gutés, 1996, p. 149).

\section{Sostenibilidad fuerte}

Este enfoque implica una mirada crítica a la sostenibilidad débil, ya que el desarrollo socioeconómico y la preservación del ambiente son contradictorios, ambos son dependientes uno del otro y poseen una relación indirecta: el crecimiento del primero implicaría una destrucción del segundo. Excepto que la dimensión de explotación pueda ser asimilada por el ecosistema. En esta línea se expresa uno de sus exponentes más importantes, el Premio Nobel alternativo Herman Daly, para quien el desarrollo sostenible no es equivalente a crecimiento económico, y su factibilidad dependerá de: 
Que la capacidad de explotación humana sea igual a la capacidad de sustentación del medio, es decir, que el área sustentada sea proporcional al área sustentante. Para lograrlo, la cantidad de habitantes y su capacidad de consumo deben limitarse, la velocidad de explotación del medio debe ser igual a la velocidad de regeneración de recursos naturales, la cantidad de emisiones deben corresponder con la capacidad de asimilación del medio y la explotación de recursos naturales debe corresponder a las tasas de extracción de recursos renovables, es decir, debe tenerse en cuenta la resiliencia del medio (Leal, 2008, p. 4).

En este enfoque no hay una creencia absoluta sobre la tecnología y la cuantificación de los recursos y su sustituibilidad, ya que existen ciertos capitales naturales que son "sensibles", difíciles de ser reemplazados: "el capital natural recibe características generales, como la de ser vulnerable, y tratarse de un capital sensible por su importancia para el funcionamiento no ya del conjunto de la economía, sino para la sociedad en todas sus dimensiones" (Neumayer, 1999, p. 97, citado en López Pardo, 2012, p. 33).

Las diferencias entre sostenibilidad débil y fuerte se sintetizan en el siguiente cuadro comparativo:

Cuadro 1. Comparación de las principales características entre la sostenibilidad débil y fuerte

Sostenibilidad débil Sostenibilidad fuerte

Concepto más antropocéntrico (tecnocéntrico) que ecocéntrico.

Concepto mecanicista.

Sostenibilidad como sinónimo de viabilidad del sistema socioeconómico.

Sostenibilidad compatible con crecimiento económico.

Capital natural sustituible por capital humano.

Constancia del capital total.

La sustentabilidad exige monetarizar el medio natural.

Creencia en un desarrollo sostenible, que en realidad es sostenido.

Medioambiente local.
Concepto más ecocéntrico que antropocéntrico.

Concepto sistémico.

Sostenibilidad como relación viable entre el sistema socioeconómico y el ecosistema.

Sostenibilidad incompatible con crecimiento.

Capital natural complementario del no sustituible por capital humano. Constancia del capital natural.

Muchos recursos, procesos y servicios naturales son monetariamente inconmensurables.

Diversas evoluciones sostenibles (históricamente han existido).

Medioambiente global y sistémico.

Fuente: Luffiego y Rabadán (2000), citado en Leal $(2008$, p. 8). 


\section{El territorio: la minería en San Juan}

Históricamente San Juan fue una provincia agroindustrial, con un importante perfil vitivinícola, pero con el marco institucional diseñado en los años noventa, el cambio de contexto en la demanda y en los precios internacionales, a partir de la década del 2000 se radican inversiones extranjeras que cambian el perfil hacia la megaminería metalífera.

Dadas las ventajas competitivas del contexto, y las comparativas que la caracterizan, la provincia se convierte en un territorio importante de inversión, producción y exportación minera, y particularmente de oro, aportando el $50 \%$ de la producción nacional.

El primer proyecto de la gran minería en una provincia que hasta el momento tuvo un desarrollo industrial relativamente bajo a nivel nacional comenzó en 2003 con la construcción del proyecto Veladero. Esta mina tenía 12.8 millones de onzas de reserva, aporta cerca del $75 \%$ de la producción provincial, y su volumen de producción se mantuvo en promedio en el orden de las 600 mil onzas por año. Su operadora es la canadiense Barrick, que en 2010 controlaba $10 \%$ de la producción de oro, convirtiéndose en uno de los capitales dominantes a nivel mundial (Abcb, 2012). Veladero prevé una vida útil de 19 años, es decir, que en 2024 terminaría de operar. "La inversión realizada para la construcción de Veladero, estimada en aproximadamente US $\$ 600$ millones, representó nada menos que el 36\% del total de Inversión Extranjera Directa en la Argentina en el año 2003 (US\$1.659 millones)" (Barrick Gold, 2009).

En 2007 comienza la construcción de la mina Gualcamayo, ubicada en Jáchal, con una inversión de US\$180 millones (Diario Las Noticias, 2009), con una extensión de 25.000 has, a 2.000 metros por sobre el nivel del mar. Operada originalmente por Viceroy, pero en 2006 es comprada por la canadiense Yamana Gold; actualmente operada por la subsidiaria Minas Argentinas S.A. (MASA). Produce plata, oro y cobre y prevé una vida útil de 10 años y una reserva de 1.2 millones de onzas de oro.

Dos años más tarde comenzó la construcción de Casposo, mina que se encuentra a 180 kilómetros de la capital de San Juan y a 2.400 metros de altura, lo que le permite una mejor accesibilidad y la posibilidad de operar todo el año con normalidad, ambas ventajas respecto a los otros proyectos. Se inicia con una reserva de 489 mil onzas y una producción anual de alrededor de 65 mil onzas de oro. Se caracteriza por producir un lingote de plata en el $99 \%$ y una vida útil de 10 años. Es la única mina a cielo abierto, con otra subterránea y una planta de procesamiento para plata (que implica una inversión 
significativamente mucho menor a la de una planta de refinamiento de oro). Asimismo, con una inversión aproximada de 45 millones de dólares (Mining Press, 2007), es la primera mina metalífera del país manejada por capitales argentinos en la actualidad, Austral (Argentina).

Los proyectos Gualcamayo y Casposo son los más pequeños en términos relativos, comprenden alrededor del $20 \%$ del oro de las reservas de Veladero. En la figura 1 se observa la localización de los proyectos.

En 2009 también se comenzó con la construcción del Proyecto binacional argentino-chileno Lama-Pascua, uno de los 10 más grandes del mundo, con una inversión estimada en 1500 millones de dólares (Mining Press, 2006). Sin embargo, fue suspendido en 2013 . $^{1}$

Según el sitio Editorial RN (2014), "entre el periodo 2003-2014, el monto global de las inversiones destinadas a los proyectos Veladero, Gualcamayo, Casposo y Lama ascendió en conjunto, a un total de ARS\$58 123595 575”

Figura 1. Ubicación de los proyectos en producción. San Juan, 2018

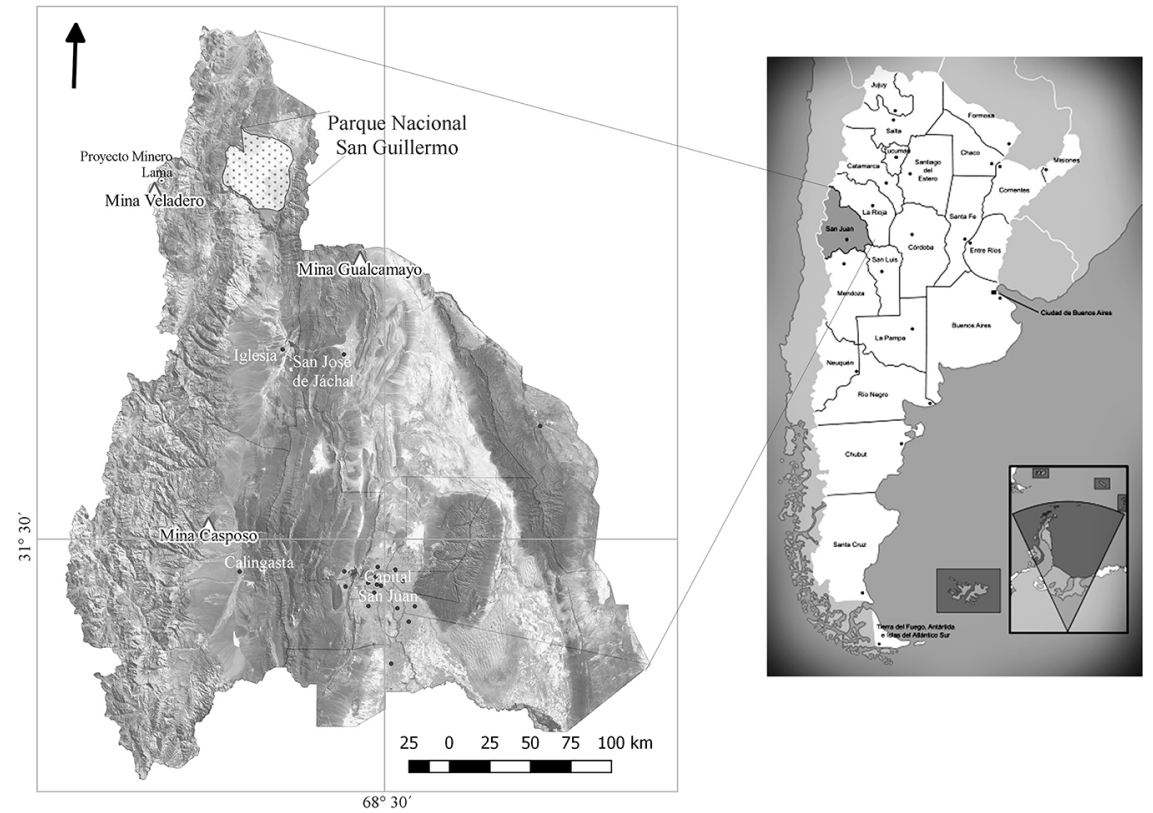

Fuente: elaborado por Huellas -Cartografía, SIG y Diseños en 3D-.

1 Este proyecto se paralizó a partir de un recurso judicial presentado por las comunidades diaguitas chilenas debido a las infracciones medioambientales que comete Barrick, que ponen en peligro los glaciares y contaminan los recursos hídricos del territorio en el que se emplazan. 


\section{DESARROLLO}

\section{La minería y el uso de los recursos naturales no renovables}

La actividad minera es un tipo de producción de consumo extensivo de recursos naturales no renovables. Según el Ministerio de Minería de San Juan, Veladero posee una concesión de agua de 110 mil litros por segundo, Gualcamayo de 116,65 1. y Casposo $12,51,{ }^{2}$ es decir, que sólo Veladero puede consumir 9.504 millones de litros por día. El mismo proyecto quema 4 millones de litros de gasoil por mes, y consume entre 18 y 20 megas.

Por el otro lado, su tipo extractivo implica la modificación del paisaje en el espacio en que se desarrolla la explotación, e incluso su destrucción. Por ejemplo las montańas y la flora y fauna nativa. El Colectivo Voces de Alerta lo expresa en la siguiente síntesis:

Mediante la utilización de explosivos se producen voladuras de montañas que permiten remover grandes volúmenes de roca. Así se forman escalones que dan lugar al "tajo abierto" u "open pit". Esto ocasiona que se movilicen tonelajes de roca crecientemente superiores a los directamente utilizados, acentuando con ello el deterioro ocasionado en el medio. Este tipo de tecnología extractiva implica que un solo emprendimiento abarque hasta mil hectáreas sólo para el área de mina -la que será completamente destruida-, llegando a remover hasta 300000 toneladas de roca diarias, y empleando por día hasta 100 toneladas de explosivos, más de 100000 litros de combustibles y decenas de toneladas de sustancias químicas de alta toxicidad (cianuro, ácido sulfúrico, xantato, mercurio, etcétera), y requiriendo un altísimo consumo hídrico y energético. Como se puede deducir, el proceso genera enormes cantidades de efluentes y desechos (en la mayoría de los casos, más de $95 \%$ de la roca extraída se convierte en residuo; se generan hasta 4 toneladas de escombros por cada gramo de oro) que quedan a perpetuidad en los lugares de explotación como "pasivos ambientales. Entre ellos, cabe mencionar el 'open pit' o 'tajo abierto' -que puede llegar a tener más de $1500 \mathrm{~m}$ de diámetro y hasta $1000 \mathrm{~m}$ de profundidad, las 'escombreras' o 'botaderos' -áreas de depósitos de estériles que pueden cubrir cientos de hectáreas- y los diques de cola o 'tranques de relaves'” (Moran, 2001; Oblasser y Chaparro Ávila, 2008, citado en Machado et al., 2011, p. 8). estadisticas/docs_pdf/pdf/consumo_de_aguas.pdf> 
En 2009, Barrick Gold recibió una demanda por "daño ambiental colectivo" ocasionado por los proyectos Pascua Lama y Veladero, ambos explotados por Barrick, y ubicados en la Reserva de Biósfera San Guillermo (RBSG), área natural protegida mundialmente. ${ }^{3}$ La demanda sostiene que "sólo en la etapa de explotación se realizaron 720 perforaciones de 100 metros de profundidad promedio" [...] e implica "la remoción de grandes cantidades de suelo que impactan directamente en el paisaje y en el patrimonio cultural alterando así el medioambiente" y que "altera la topografía y el paisaje de la zona siendo "un gran generador de residuos domésticos, industriales no peligrosos, industriales peligrosos y patogénicos" (Dictamen Vargas, Ricardo Marcelo C/ San Juan, Provincia de y Otros, 2009, p. 3).

El daño es confirmado además por un documento elaborado por la Administración de Parques Nacionales (APN) institución que originalmente tenía a su cargo la elaboración de un Plan de Manejo de la Reserva. El mismo arrojó un resultado negativo para el desarrollo de la minería en la zona, advirtiendo en materia ambiental el potencial peligro que implica la actividad minera en la reserva. ${ }^{4}$

El dictamen observa que aun cuando en el área de PNSG no se hiciera minería ésta era afectada indirectamente, dado el límite con los ríos Blanco y La Palca (cuyo aporte principal provenía del río Las Taguas utilizado por Veladero y Lama), fuentes hídricas de consumo de los animales que habitaban aquél (APN, 2013).

Además del consumo y destrucción de recursos finitos, la experiencia da cuenta de múltiples casos de contaminación de recursos para los cuales la tecnología aún no ha encontrado un sustituto artificial, como lo es el agua. En el estudio de caso abordado, Barrick Gold contaminó las aguas de ríos y opera en zonas de glaciares, destruyendo así una fuente vital para las poblaciones locales.

En primer término y referente a la contaminación de los ríos, entre 2015 y 2016 Barrick Gold provocó al menos tres derrames de solución cianurada en San Juan que contaminaron los ríos Potrerillos, Jáchal, Las Taguas, Palca y Blanco según informe de la División Operaciones del Departamento de Delitos Ambientales de la Policía Federal Argentina (TN, 2016). El primero

La RBSG se caracteriza por tener la mayor concentración de guanacos y vicuńas, entre otras especies de fauna y flora únicas y propias de la zona. También es una zona de estudio arqueológico, dada la importancia de su patrimonio histórico. Pero, fundamentalmente lo que posee es agua, ya que es un territorio de localización de importantes cuencas hídricas, glaciares y periglaciares. 
fue el 12 de septiembre de 2015 en el río Potrerillos, ${ }^{5}$ y la evidencia de contaminación fue demostrada por un análisis realizado por una investigadora de la Universidad Nacional de Cuyo (uncuyo) de la provincia de MendozaArgentina, que detectó la presencia de metales pesados en el río (manganeso y aluminio) superando ampliamente lo permitido por la ley ${ }^{6}$ (claro indicador que las aguas estaban contaminadas) (Fernández Rojas, 2015).

Posteriormente, el gobierno provincial encargó el análisis de impacto a la Oficina de las Naciones Unidas de Servicios para Proyectos (UnOps). El informe técnico elaborado por el Programa de las Naciones Unidas para el Medio Ambiente (PNUMA) confirmó la contaminación en la zona 0 , es decir, la más cercana al derrame (UNOPs, 2016, p. 8).

Los derrames dejaron en evidencia que la empresa minera estaba operando sin el seguro ambiental obligatorio, establecido en el artículo 22 de la Ley General de Ambiente No 25.675. La empresa reconoció la infracción, alegando que no lo tenía porque es un servicio no existente en el mercado argentino. ${ }^{7}$

En abril de 2018, un análisis realizado en el afluente del río Jáchal arrojó cifras que evidenciaron la presencia de metales pesados con niveles excedentes a lo permitido por la ley, ${ }^{8}$ por lo que se presume que se habrían ocultado dos derrames más.?

En segundo término y referido a glaciares, la minería en San Juan (y también en Chile) se asentó sobre permafrost, suelo congelado, glaciares y periglaciares. Los glaciares Toro 1, Toro 2 y Esperanza estaban dentro del área del Proyecto Pascua Lama. El valle de lixiviación de Veladero, por ejemplo, se encuentra sobre una enorme zona de ambiente periglacial. Así lo certifica el Informe de Impacto Ambiental (2002) elaborado por la consultora Knight Piésold S.A. para Minera Gold S.A., la subsidiaria de Barrick Gold. En el apartado de "Descripción de cuerpos de aguas superficiales" se afirma la presencia de "glaciares que se ubican en las cabeceras de las cuencas de los Arroyos Canito, Turbio y de Los Amarillos” (p. 45); y de glaciares de roca (p. 16).

\footnotetext{
Véase informe unOPS (2016, p. 1).

Véase informe elaborado por la uncuYo, Fernández Rojas (2015) <http://www.unidiversidad.com. ar/el-derrame-de-la-barrick-enveneno-el-agua-de-jachal>

$<$ http://www.panoramaminero.com.ar/noti66.htm>

Tiempoar <https://www.tiempoar.com.ar/articulo/view/76139/veladero-denuncian-dosgrandes-derrames-que-fueron-ocultados>

Se supondría que la decisión esconde la intención de no cerrar el proyecto minero, ya que en Argentina el Código Minero indica en su artículo 264, inciso "e" textualmente que "en caso de TRES (3) infracciones graves se procederá al cierre definitivo del establecimiento".
} 
En Chile, la Dirección General de Aguas, dependiente del Ministerio de Obras Públicas de Chile demostró que la explotación en Pascua de los glaciares Toro 1, Toro 2 y Esperanza disminuyeron su volumen entre 56 y $70 \%$ desde 2005 y hasta 2013.

\section{La minería y la debilidad del crecimiento económico}

En este apartado se abordarán tres variables productivas a efecto de analizar la incidencia de la actividad minera en el territorio.

\section{El oro y el Producto Bruto Geográfico $(P B G)^{10}$ local}

Los sectores que registraron mayor dinamismo en el periodo entre 2003 (cuando comienza la construcción de Veladero) y 2015, fue el de la construcción y el de minas y canteras (particularmente carburo de calcio, cal y ferrosilicio), con una tasa de crecimiento de 12.79 y $11.79 \%$, respectivamente (véase cuadro 2). Ambos sectores están directamente vinculados a la minería extractiva, ya que son proveedores de servicios e insumos a la cadena minera.

Se observa en el total del rubro construcciones en las cuentas macroeconómicas de la provincia, que la construcción del sector minero creció de 7.5\% en el 2003 a $47.5 \%$ en 2015 .

El rubro minas y canteras es el segundo sector que mayor tasa de crecimiento (11.7\%) registró entre 2003-2015, ${ }^{11}$ aunque no tiene un aporte considerable en el PBG, ya que comprende sólo el $0.48 \%$ en 2015 .

En síntesis, el mayor aporte productivo vinculado -aunque de manera indirecta- a la minería es la tracción de algunas actividades económicas, aunque no sean las de mayor aporte en el PBG -entre la construcción y los minerales no metalíferos comprenden un 7.67\% del total del PBG en 2015 .

10

El PBG mide los valores de los bienes y servicios producidos en un determinado lugar y tiempo. Se utiliza para valorar las producciones de las provincias, mientras que el total del país se mide a través del PIB.

11 Se toma ese periodo porque 2003 marca el inicio de la construcción del campamento Veladero, para lo cual se demandaron insumos provenientes del rubro minas y canteras; por ejemplo: cal, carburo de calcio, carbonato de calcio. El 2015 es el último dato disponible. 
Cuadro 2. Tasa de crecimiento en el PBG por sector económico. San Juan, 2003-2015

\begin{tabular}{lc}
\hline \multicolumn{1}{c}{ PBG San Juan } & 8.05 \\
\hline Agropecuario & 2.29 \\
Minero industrial y roca de aplicación & 11.79 \\
Industrias manufactureras & 7.12 \\
Electricidad, gas y agua & 7.88 \\
Construcciones & 12.79 \\
Comercio, restaurantes y hoteles & 9.21 \\
Transporte y comunicaciones & 7.09 \\
Establecimientos financieros, bienes inmuebles y servicios a las empresas & 5.90 \\
Servicios soc., comun. y pers. & 10.53 \\
\hline
\end{tabular}

Fuente: elaboración propia con base en IIEE, San Juan, 2015.

Por otro lado, el rubro que da cuenta de la producción de oro es el de industrias manufactureras (cuenta Metales Básicos, subcuenta Metales no Ferrosos) que hasta 2004 registraba un valor nulo. Sin embargo, en el PBG de San Juan registra un crecimiento que va de ARS\$2 070.9 en 2005 a ARS\$364 331.9 en 2015. La tendencia comienza en 2005 con la entrada en producción de Veladero, y fue en aumento con el aporte de Gualcamayo (2007) y Casposo (2009) con un continuo crecimiento que se interrumpió en 2013 por la caída del precio del oro, el incremento de los costos y la suspensión de Pascua Lama.

A pesar de la caída, en 2015 comprendió 38\% de lo aportado por manufacturas (rubro en el que se contabiliza) y $5.5 \%$ de lo producido en la provincia en miles de pesos.

Como se observa en el cuadro 3, en la década 2005-2015 el oro tuvo una tasa de crecimiento de $60 \%$, y aportó en promedio $4.1 \%$ al PBG de San Juan y $31.7 \%$ (en promedio) al sector de las industrias manufactureras.

Las inversiones extranjeras en la minería no modificaron la estructura productiva de un espacio local. Efectivamente, antes de la megaminería San Juan tenía una matriz fuertemente vinculada al gasto estatal y a los servicios, y eso no sólo no se modificó sino que se profundizó en los últimos años. Las cifras dan cuenta que al 2015 la economía de San Juan no está asentada en actividades productivas, sino en gasto público, de servicios financieros e inmobiliarios. 
Más de la mitad de lo producido en la economía provincial se genera en los gastos de los sectores públicos (predominando las erogaciones en educación y salud) y financiero.

Claramente, y en la misma línea de pensamiento de Harvey (2003), la forma de reproducción del capital extractivo está vinculada más a la acumulación por despojo que a la extensión en sí misma del capital.

\section{Exportaciones metaliferas de San Juan}

Las exportaciones de San Juan crecieron desde 2003 hasta 2011, pero fue a partir de 2012 que hubo una caída, tal como se oberva en el cuadro 4. En 2014, la estructura exportable se concentraba en manufacturas de origen industrial (MOI) con 84\%, básicamente en el rubro de metales metalíferos (88\%). El resto se distribuyó en $12 \%$ de manufacturas de origen agropecuario (MOA) y $4 \%$ de productos primarios. En MOI, $84 \%$ de los envíos son de oro. En el mismo año, $70 \%$ de las exportaciones sanjuaninas son del mismo metal. Estos procesos ponen de manifiesto la perspectiva cepalina que caracteriza a las economías periféricas heterogéneas y especializadas, ${ }^{12}$ en los que existen sectores modernos con poco efecto de arrastre en el resto de las actividades domésticas y con una demanda que se abastece fundamentalmente con importaciones, sobretodo en una provincia cuyo desarrollo manufacturero es mínimo.

En 2016, San Juan exportó un total de 1.263 millones de dólares, lo que equivale a un $2.2 \%$ del total nacional. El $73 \%$ de las ventas locales al mercado internacional corresponden al oro, y el destino principal -en la misma proporción- es Canadá, país de origen de Barrick Gold, el mayor operador de oro en San Juan. Las fluctuaciones están fuertemente atadas al comportamiento del precio del oro, a mayor precio internacional, mayor dinamismo en las exportaciones locales y viceversa. ${ }^{13}$

"La especialización (o desarticulación) posee los siguientes indicadores: concentración de la exportación en unos pocos productos primarios; la ausencia, en la industria, de diversificación horizontal, complementariedad sectorial e integración vertical; la presencia de sectores modernos en forma de 'enclaves', sin apenas efectos internos de arrastre; y la existencia de una demanda interna de productos manufacturados básicamente abastecida con importaciones" (Petit Primera, 2013, p. 128). Shanghái), a partir de la demanda y de los stocks o inventarios disponibles" (мнуғр, 2016, p. 10). 


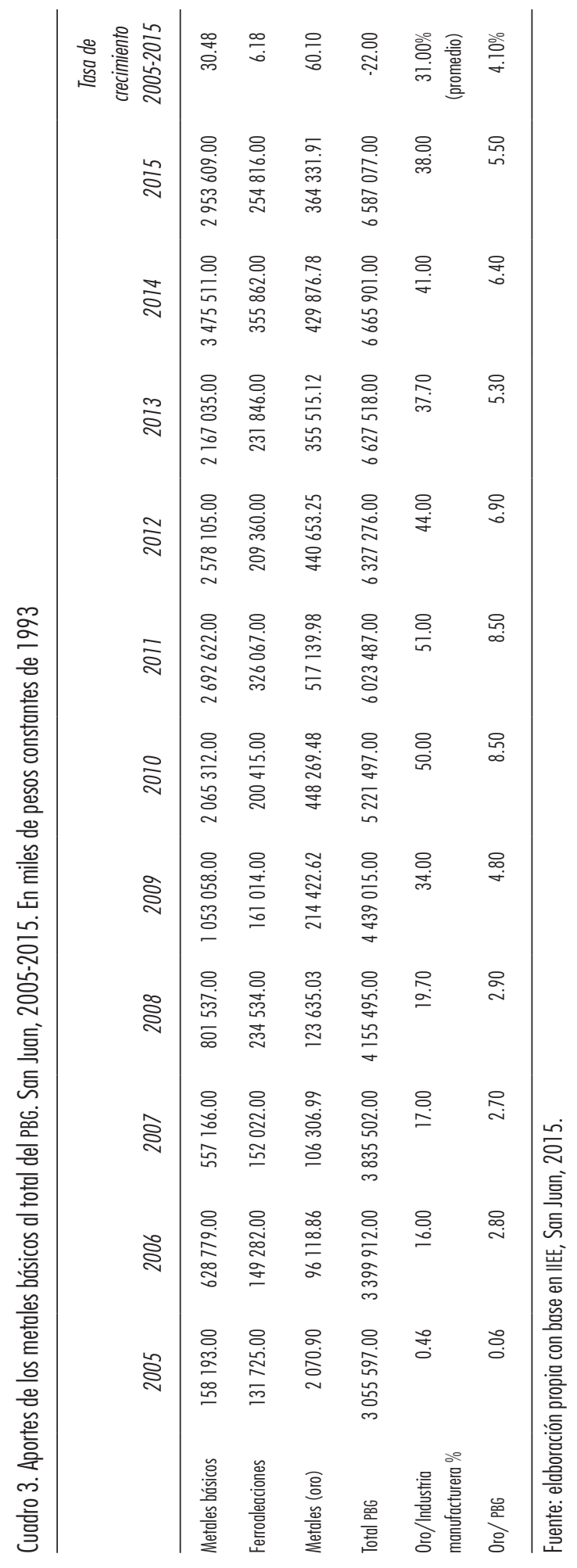


Estas características exponen a la estructura exportable de la provincia a cierta vulnerabilidad comercial, ya que depende de las fluctuaciones en el mercado internacional de un solo producto (el oro), y del comportamiento de una sola empresa (Barrick Gold). Evidencia un delicado modelo de base exportable que permitió un rápido crecimiento económico (el mismo capaz de poner en jaque a la economía provincial en una crisis), y un proceso desarrollo a mediano plazo frágil para el territorio.

La cadena metalífera le permitió un mejor posicionamiento a San Juan que, históricamente tuvo una participación mínima en el total nacional de exportaciones -sólo $0.6 \%$ en el 2000-, caracterizándose por una estructura exportable vinculada fundamentalmente a su estructura agroproductiva (en el $2000,58 \%$ de sus ventas externas estaban comprendidas por productos vitícolas, hortícolas y olivícolas). A partir de 2005, con las primeras exportaciones de oro, la provincia mejoró su participación a nivel nacional y cambió su perfil exportable hacia la venta de bienes mineros. Como consecuencia, en 2016 se ubicó en el séptimo lugar en el ranking de exportaciones provinciales.

El siglo pasado, los territorios de escaso desarrollo se insertaron en la economía global a través de las exportaciones de productos primarios con poco o ningún procesamiento industrial, en este caso el bullón dorado. La clásica división internacional del trabajo se reproduce contemporáneamente evidenciando escasa evolución respecto a tiempos pasados, lo que no es necesariamente un indicador de desarrollo. El crecimiento sólo se evidencia en actividades vinculadas a la actividad exportadora, el resto de las ramas industriales o actividades económicas en la provincia tienen un desarrollo relativamente bajo, por ejemplo, la vitivinicultura.

Lejos de afianzar una estructura comercial exportable que dinamice la industria local y nacional, las inversiones megamineras le imprimen vulnerabilidad comercial en la canasta exportable. La concentración de las exportaciones en un solo producto (en San Juan 70\% de las ventas externas corresponden al envío de oro) aporta fragilidad, ya que depende de las fluctuaciones en el mercado internacional de un solo producto (el oro), y del comportamiento de una sola empresa (Barrick Gold). Evidencia un delicado modelo de base exportable que permitió un rápido crecimiento económico (el mismo capaz de poner en jaque a la economía provincial en una crisis), y un proceso desarrollo sustentable débil y enclenque para el territorio. 


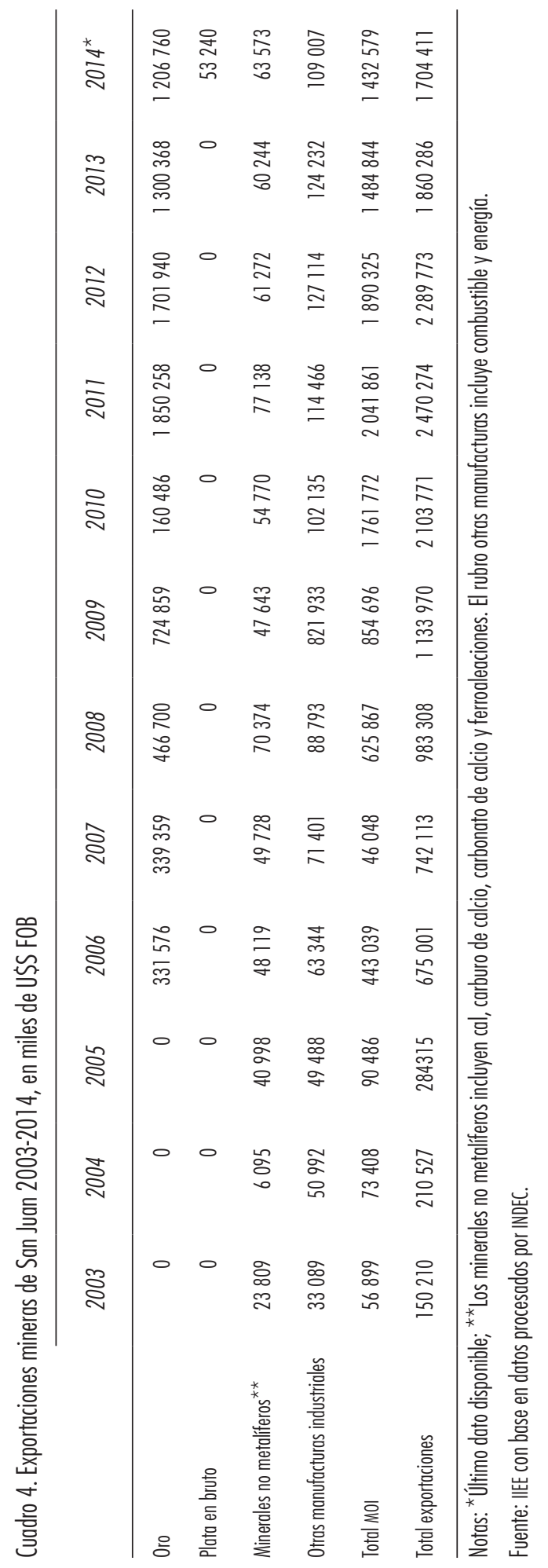




\section{Empleo en la minería metalifera}

En 2015 la cadena metalífera nacional empleó un total de 10.956 trabajadores (мнуғр, 2016), de los cuales $25.5 \%$ eran originarios de San Juan. La generación de puestos de trabajo a nivel nacional tuvo una tendencia creciente respecto a la década de los noventa: en 1996 se empleaban 2420 trabajadores, en 2006 se registraron 4788 .

No obstante, en el total provincial es una de las de menor participación en la estructura laboral. Todas las empresas vinculadas a la rama de minas y canteras (incluidas las no metalíferas) absorben 3302 sanjuaninos, lo que equivale sólo a 3.8\% del empleo local en el primer trimestre de 2016, y menos de $2 \%$ de la PEA provincial. ${ }^{14}$ Una cifra realmente pequeña para una actividad económica que se aparecía como la gran fuente generadora de empleo.

La etapa de construcción -desde la preparación de la mina para extraer el mineral hasta la instalación de procesamientos- es la de mayor demanda de mano de obra. Sólo la de construcción de Veladero, que comienza en 2003, demandó 3800 trabajadores y el proyecto Pascua Lama (el proyecto más grande que comenzó en 2009) llegó demandar alrededor de 10 mil puestos de empleo, que quedaron cesantes cuando el proyecto se suspendió en 2013. Si bien la demanda está conformada por trabajadores de todas las ramas, esta tendencia se percibe claramente en el sector de la construcción que pasa de absorber 1694 trabajadores en 2003 a 17791 en 2013. En 2014 cayó a 12857.

La cifra de trabajadores directos no es significativa, aunque los defensores de la actividad suponen que la mayor tracción se encuentra en la generación de empleo indirecto: "por cada empleo generado en la nómina de una empresa minera, las mismas requieren la generación de dos puestos de trabajo adicionales en empresas proveedoras y contratistas" (Abcb, 2012, p. 55). Es decir, en términos absolutos la demanda en 2016 de empleo indirecto para el sector osciló en alrededor de 6600 puestos de trabajo en la provincia.

Los proyectos mineros de gran envergadura requieren de un uso intensivo de capital, en relación con las actividades agrícolas que son extensivas en el uso de mano de obra. De esta manera, mientras estas últimas representan 10\% del empleo provincial, la minería entera (incluida la no metalífera) comprende 4\% en el 2015 (Observatorio de Empleo y Dinámica Empresarial). 
A ello se suma que la demanda de empleo -en una commodities como el oro- está vinculada al contexto internacional y que cuando cae su precio internacional la incidencia laboral es directa, que se evidenció entre 2014 y 2016 cuando se comenzó con un plan de despidos de 250 empleados, en el que se incluían "retiros voluntarios" en la mina Casposo, impactando en la caída del precio internacional de los metales.

Por otro lado, aun cuando el empleo demandado es relativamente bajo, uno de los aspectos que opera como un importante factor de legitimación de la actividad, es el nivel de remuneración. En efecto, la minería es la actividad que paga los salarios más altos en San Juan; mientras que un trabajador de la agricultura $^{15}$ tiene una remuneración promedio de ARS\$8.711 por mes, en la minería se ganaba ARS\$57.354, en 2016. Equivalente a 283\% más que el sueldo promedio en la provincia en términos absolutos. En una provincia de bajo desarrollo, la brecha salarial que impulsa la actividad extractiva mejora las condiciones materiales de reproducción.

Como se puede observar en el cuadro 5, la remuneración a la actividad minera creció mucho más que el resto de las actividades económicas. Sin embargo, la tendencia en el largo plazo es una tasa de crecimiento relativamente menor que el resto de las actividades: la extracción de minerales metalíferos registra la tasa de crecimiento más baja en relación con el resto de las actividades en los 14 años analizados.

A pesar de haber recibido grandes inversiones en la década del 2000 en el sector de la minería metalífera, San Juan sigue conservando un valor promedio de sus salarios por debajo de la media nacional. De esta manera, mientras que el promedio de las remuneraciones en el total nacional era de ARS\$20.295 en 2016, para San Juan era de ARS\$16.203 (sIPA, 2016). Podría inferirse entonces que la minería no provoca un efecto arrastre en el valor de la remuneración del resto de las actividades económicas en la provincia de San Juan.

Respecto a la incidencia de la minería en los departamentos en los que se encuentran los proyectos es relativamente baja. En 2017 el intendente de Iglesias (Departamento en el que se encuentra Veladero) afirmó que de 5 mil personas que alcanzan la población económicamente activa, 3 mil están desempleadas, es decir, 60\%. En Calingasta (Casposo) el desempleo asciende a $35 \%$, mientras que en Jáchal (Gualcamayo) a 20\%.

El trabajo minero transformó el escenario laboral en la provincia, pues se pagaban sueldos altos que mejoraron la calidad de vida, se adquirieron nuevas 
capacidades de trabajo, se modificaron las formas de organización del trabajo (sobre todo en lo que respecta a las horas y días), a la vez que se asumían mayores riesgos en términos de salud, seguridad y vínculos socio-familiares para los nuevos trabajadores. También se transformaron las relaciones laborales, creció la tercerización del empleo. Su búsqueda es "delegada en consultoras y empresas de servicios eventuales, tales como Manpower, Orico y втz Minera. En minas como Bajo La Alumbrera, Veladero y Gualcamayo se registra un alto nivel de tercerización laboral, lo cual ha implicado la proliferación de los llamados 'contratos a prueba' y la exención de responsabilidad de las empresas mineras frente a eventuales despidos" (Gómez Lende, 2016, p. 158).

La década 2005-2015 da cuenta que los indicadores de empleo, exportación y regalías no arrojan cifras económicas de incidencia positiva en el territorio, por el contrario se abrió un proceso de conflictos socioambientales originados en daños irreversibles.

Cuadro 5. Evolución de asalariados registrados del sector privado por rama de actividad Primer trimestre de 2002 - primer trimestre de $2016^{\star}$. San Juan

\begin{tabular}{|c|c|c|c|c|c|c|}
\hline Ramas de actividad & $\begin{array}{c}\text { Primer } \\
\text { trimestre } \\
2002\end{array}$ & $\begin{array}{l}\text { Primer } \\
\text { trimestre } \\
2003\end{array}$ & $\begin{array}{c}\text { Primer } \\
\text { trimestre } \\
2006\end{array}$ & $\begin{array}{c}\text { Primer } \\
\text { trimestre } \\
2010\end{array}$ & $\begin{array}{c}\text { Primer } \\
\text { trimestre } \\
2013\end{array}$ & $\begin{array}{c}\text { Primer } \\
\text { trimestre } \\
2016\end{array}$ \\
\hline $\begin{array}{l}\text { Agricultura, ganadería, caza } \\
\text { y silvicultura }\end{array}$ & 9344 & 9424 & 11943 & 11070 & 11226 & 8486 \\
\hline $\begin{array}{l}\text { Explotación de minas } \\
\text { y canteras }\end{array}$ & 669 & 763 & 1919 & 3016 & 3874 & 3302 \\
\hline Industria manufacturera & 10182 & 9939 & 12889 & 15306 & 16343 & 14809 \\
\hline Electricidad, gas y agua & 356 & 353 & 345 & 333 & 358 & 341 \\
\hline Construcción & 2757 & 1694 & 7242 & 8464 & 17791 & 11885 \\
\hline $\begin{array}{l}\text { Comercio al por mayor } \\
\text { y al por menor }\end{array}$ & 7841 & 7526 & 10033 & 13494 & 14491 & 14664 \\
\hline Hotelería y restaurantes & 791 & 775 & 1331 & 2251 & 3878 & 2951 \\
\hline $\begin{array}{l}\text { Servicios de transporte, } \\
\text { de almacenamiento y de } \\
\text { comunicaciones }\end{array}$ & 2864 & 2827 & 3466 & 4831 & 5896 & 5502 \\
\hline $\begin{array}{l}\text { Intermediación financiera y } \\
\text { otros servicios financieros }\end{array}$ & 1321 & 1091 & 1121 & 1255 & 1609 & 1558 \\
\hline
\end{tabular}




\begin{tabular}{lcccccc}
\hline Ramas de actividad & $\begin{array}{c}\text { Primer } \\
\text { trimestre } \\
2002\end{array}$ & $\begin{array}{c}\text { Primer } \\
\text { trimestre } \\
2003\end{array}$ & $\begin{array}{c}\text { Primer } \\
\text { trimestre } \\
2006\end{array}$ & $\begin{array}{c}\text { Primer } \\
\text { trimestre } \\
2010\end{array}$ & $\begin{array}{c}\text { Primer } \\
\text { trimestre } \\
2013\end{array}$ & $\begin{array}{c}\text { Primer } \\
\text { trimestre } \\
2016\end{array}$ \\
\hline $\begin{array}{l}\text { Servicios inmobiliarios, } \\
\text { empresariales y de alquiler }\end{array}$ & 3442 & 3492 & 6302 & 7584 & 8858 & 7588 \\
$\begin{array}{l}\text { Enseñanza } \\
\text { Servicios sociales y de salud }\end{array}$ & 2094 & 2074 & 2202 & 3063 & 3591 & 3564 \\
$\begin{array}{l}\text { Servicios comunitarios, } \\
\text { sociales y personales n.c.p. }\end{array}$ & 2586 & 2553 & 2631 & 3043 & 4411 & 4399 \\
\hline Total & 45843 & 44081 & 64203 & 77955 & 98440 & 85797 \\
\hline
\end{tabular}

Notas: *Años seleccionados para observar si los cambios importantes en las empresas mineras se reflejan en las estadísticas de trabajo. Por ejemplo, en 2003 comienza la construcción de Veladero, y en 2005 la puesta en marcha con exportaciones incluidas. Ello supone un aumento en la demanda de mano de obra en general impulsada por la actividad. En 2009 comienza a construirse Pascua Lama y es suspendida en 2013, eso también supondría cierta incidencia en la demanda de trabajadores sanjuaninos. Para todas esas fechas se observa el año posterior.

Fuente: elaboración propia con base en Observatorio de Empleo y Dinámica Empresarial, MTESS.

\section{CONCLUSIONES: LA MINERÍA Y EL DESARROLLO INSOSTENIBLE}

El análisis aportó evidencias sobre el posible crecimiento que pudiera generar la minería que no va acompañado de la preservación del medioambiente y la cultura del lugar. Se contaminaron ríos y se propició la potencial destrucción de glaciares, extinguiendo uno de los recursos estratégicos para la vida humana: el agua. Ello pone en peligro el bienestar presente, así como el de futuras generaciones. Tampoco existe un aparato estatal que tenga un papel activo en el control o preservación socioambiental.

El crecimiento y la dinamización no son necesariamente una consecuencia directa de la minería. Como se observó a lo largo de este trabajo, en San Juan no es una actividad que dinamice la economía provincial. El crecimiento económico es un discurso que se utiliza sólo para legitimar la actividad. Los datos de empleo, exportación y regalía demuestran que no es suficiente como para garantizar el bienestar de la población a largo plazo.

En San Juan aportan sólo 4\% en promedio entre 2005 y 2015 al PBG, una baja oferta de empleo local directo y vulneran la estructura exportable. Es evidente que existe cierta contradicción entre la disposición y la apropiación de 
recursos naturales no renovables, que tienen un significativo valor en el orden mundial, pero una incidencia relativamente baja en el territorio, que no garantiza un proceso de desarrollo sostenible fuerte a mediano o largo plazo. Los impuestos que las empresas mineras pagan, como las regalías, ${ }^{16}$ no se han visto materializados en mejoras en la infraestructura en los departamentos mineros (Iglesia, Calingasta y Jáchal). Tras 15 años que comenzara la construcción del primer gran proyecto todavía no es posible verificar una transformación estructural del territorio que dé cuenta de una mejora en las condiciones de hábitat en las poblaciones locales.

No hay grandes obras públicas que aporten la calidad o el desarrollo de los espacios locales; no hay más ni mejores hospitales que optimicen el servicio de salud; no hay mejor infraestructura educativa como producto de la inversión directa proveniente de la minería y las rutas y camino de acceso e internas no se han mejorado tampoco. De igual forma, no había antes ni se ha creado últimamente un transporte de línea interno público de pasajeros, los turistas que se trasladan hasta allí no tienen cómo movilizarse internamente; tampoco se instaló el gas ni las cloacas.

En materia productiva, el empleo no es significativo y la cantidad de proveedores locales no es lo suficientemente importante como para modificar la estructura de las condiciones de desarrollo de ambos departamentos.

No hay mejores procesos de gobernanza; los ciudadanos viven en un constante estado de conflicto e incertidumbre social, se sienten excluidos de la toma de decisiones políticas que les atañe directamente (plebiscito) y no hay mecanismos de acceso a una información que sea clara y certera.

Los medios de comunicación (excepto los comunitarios) viven en su mayoría de la pauta publicitaria minera, por lo que las posibilidades de cuestionar cualquier práctica que afecte al desarrollo del espacio son relativamente bajas y la cobertura mediática es baja.

No hay precio de mercado para el agua, cuya fuente es destruida por la actividad minera afectando ríos y glaciares. El agua, la flora y la fauna autóctona, así como el aire no son reemplazables, tal como lo proponían las teorías de la década de los setenta. $\mathrm{O}$ al menos no lo son hasta el momento, ya que no se ha creado tecnología o capital que lo sustituya. No hay innovaciones tecnológicas que no destruyan el medio ambiente en la explotación minera, y cuando el

16

Las regalías son pagos que las empresas mineras deben realizar en concepto de compensación por la explotación de recursos no renovables. Consiste en un impuesto sobre el valor bruto de los valores extraídos y en Argentina está regulado por el artículo 22, de la Ley Nacional № 24.196. 
mineral se haya agotado y el proyecto alcanzado su vida útil el stock global no será mayor, sino menor.

En Latinoamérica y demás regiones periféricas, la lógica de las transnacionales es distinta: la inversión en tecnología no es usual, en general es importada de sus países de origen. En Argentina particularmente la fracción del capital dominante posee ámbitos de acumulación privilegiada (Castellani, 2012), caracterizándose por crecer al amparo del Estado y no por las innovaciones producto de la inversión privada. Esa lógica se combina con una importante debilidad institucional, característica de los espacios locales que se insertan a la dinámica mundial con producciones nuevas.

En San Juan, los departamentos mineros no tenían una tradición histórica en la minería metalífera, por tanto, no existían técnicos preparados, ni habitantes conscientes y formados, tampoco existían aparatos estatales con capacidades para demandar desarrollo y controlar la destrucción de los recursos naturales. En algunos casos, fueron los profesionales de las empresas mineras los que proponían proyectos a los gobiernos locales, imponiendo convenientes -para las transnacionales- estilos de desarrollo. Asimismo, dicha debilidad institucional tiene como consecuencia la transgresión de cualquier norma que destruya el ambiente, e incluso del pago de determinado seguro ambiental, como lo evidencia el caso de Barrick Gold luego del primer derrame.

En síntesis, cabe interrogarse: ¿¿realmente podría establecerse el valor de destrucción de un elemento vital para las poblaciones locales? Suponiendo que los recursos naturales son conmensurables, ¿cómo se medirían la destrucción de la cultura y la historia de una comunidad que debería emigrar por falta de agua? ¿Bajo qué consideraciones éticas?

Más allá de los debates y las reflexiones en el campo académico, el desarrollo sostenible en el sistema capitalista, cuya búsqueda constante de acumulación de excedente implica la destrucción ambiental, social, cultural e histórica en territorios locales con importantes reservas naturales, se convierte sólo en una quimera. 


\section{BIBLIOGRAFÍA}

Abcb (2012), Dimensionamiento del aporte económico de la minería en Argentina, Argentina, Cámara Argentina de Empresarios Mineros (CAEM). Recuperado de <http://www.miningpress.com/media/briefs/abeceb_15.pdf >

Administración de Parques Nacionales (APN) (2013), Plan de Manejo Parque Nacional San Guillermo y Propuesta de Manejo Integrado de la Reserva de Biosfera San Guillermo. Recuperado de <https://www.losquesevan.com/ plan-de-manejo-del-parque-nacionalsan-guillermo.1617>

Barrick Gold (2009), Mina Veladero impulsa el crecimiento económico y social de San Juan, página web oficial. Recuperado de <https://barricklatam.com/ mina-veladero-impulsa-el-crecimiento-economico-y-social-de-san-juan/ barrick/2012-06-05/161602.html>

Cabeza Gutés, M. (1996), “The Concept of Weak Sustainability”, Ecological Economics 17. Recuperado de <https://campusvirtual.univalle.edu.co/ moodle/pluginfile.php/682139/mod_label/intro/CABEZA-Weak-Sustainability.pdf>

Castellani, A. (2012), Recursos públicos, intereses privados. Ámbitos privilegiados de acumulación. Argentina 1966-2000, Argentina, unsam Edita.

Diario Las Noticias (2009), "La mina de oro Gualcamayo, en Jáchal, comienza a producir comercialmente", nota periodística, 30 de julio. Recuperado de <http://www.diariolanoticias.com/mostrarnoticial.php? id_noticia $=3042>$

Dictamen Vargas, Ricardo Marcelo C/ San Juan, Provincia de y Otros s/ daño ambiental (2009), Argentina. Recuperado de <http://www.mpf.gov.ar/ dictamenes/2009/monti/agosto/6/v_175_1_xliii_vargas.pdf>

Editorial RN (2014), "La minería sigue siendo, el principal motor del desarrollo...". Recuperado de <http://www.editorialrn.com.ar/index.php? option=com_content\&view=article \&id=1133:la-mineria-sigue-siendo-elprincipal-motor-del-desarrollo\&catid=14:nacional \&Itemid =599>

Falconí, F. (2002), Economía y desarrollo sostenible. ¿Matrimonio feliz o divorcio anunciado? El caso de Ecuador, Ecuador, FLACso.

Fernández Rojas, J. (2015), "El derrame de la Barrick envenenó el agua de Jáchal", informe en el portal web Unidiversidad perteneciente a la Universidad Nacional de Cuyo, 3 de octubre. Recuperado de <http://www.unidiversidad.com.ar/el-derrame-de-la-barrick-enveneno-el-agua-de-jachal>

Gómez Lende, S. (2016), "Psicoesfera y minería metalífera en la Argentina: el mito de la creación de empleo en las provincias de Catamarca y San Juan", 
Geografía, vol. 25, núm. 1, Brasil, Universidade Estadual de Londrina, enero-junio. Recuperado de <http://www.uel.br/revistas/uel/index.php/ geografia/article/view/25362>

Harvey, D. (2003), El nuevo imperialismo, Madrid, Akal.

Informe de Impacto Ambiental Veladero (2002), Knight Piésold Consulting. Recuperado de <http://center-hre.org/wp-content/uploads/2013/05/veladero-informe-de-impacto-ambiental-exploracion.pdf>

Instituto de Investigación Económicas y Estadísticas (2015), Tasa de crecimiento en el PBG por sector económico, San Juan, 2003-2015.

Leal, G. (2008), Debate sobre la sostenibilidad. Desarrollo conceptual y metodológico de una propuesta de Desarrollo Urbano Sostenible, Pontificia Universidad Javeriana, Bogotá, Colombia. Recuperado de <http://www. javeriana.edu.co/Facultades/Arquidiseno/maeplan/publicaciones/documents/DebatesobrelaSostenibilidad_000.pdf>

López Pardo, I. (2012), Sostenibilidad "débil" y "fuerte" y democracia deliberativa -el caso de la Agenda 21 local de Madrid. (Tesis doctoral), Universidad Carlos III de Madrid. Recuperado de <https://e-archivo.uc3m.es/handle/10016/16270>

Machado, H., Svampa, M., Viale, E., Giraud, M., Wagner, L., Antonelli, M., Giarraca, N. y Teubal, M. (2011), 15 mitos y realidades de la minería transnacional en Argentina. Guía para desmontar el imaginario prominero, Argentina, Colectivo Voces de Alerta. Recuperado de <http://biblioteca. clacso.edu.ar/Argentina/iigg-uba/20161025033400/15mitos.pdf>

Mining Press (2007), "Casposo responderá a observaciones a su IIA antes del plazo", nota periodística, 15 de agosto. Recuperado de <http://www.miningpress.com/nota/24305/casposo-respondera-a-observaciones-a-su-iiaantes-del-plazo>

(2006), "Cómo será Pascua Lama”, nota periodística, 21 de febrero. Recuperadode<http://www.miningpress.com/nota/13886/como-sera-pascua-lama>

Ministerio de Hacienda y Finanzas Públicas (мнуғр) (2016), Informes de cadenas de valor: minería metalifera y rocas de aplicación, año 1, núm. 2, Argentina, mayo. Recuperado de <http://www.economia.gob.ar/peconomica/ docs/SSPE_mineria_metalifera_rocas.pdf>

Observatorio de Empleo y Dinámica Empresarial. Ministerio de Producción y Trabajo, <www.trabajo.gob.ar>

Pañeda, C. (1994), "El mundo que viene", Revista de Economía Aplicada, vol. 5, núm. II, Alianza, Madrid. Recuperado de <http://www.revecap. $\mathrm{com} /$ revista/numeros/05/pdf/paneda.pdf> 
Petit Primera, J. (2013), "La teoría económica del desarrollo desde Keynes hasta el nuevo modelo neoclásico del crecimiento económico", Revista Venezolana de Análisis de Coyuntura [en línea], XIX, enero-junio. Recuperado de <http://www.redalyc.org/articulo.oa?id=36428605012>

Sistema Integrado de Previsión Argentino (sIPA) (2016), Estudios y Estadísticas Laborales, Ministerio de Producción y Trabajo. Disponible en $<\mathrm{http}: / /$ www.trabajo.gob.ar/estadisticas/index.asp>

Solow, R. (1991), "Sustainability: An Economist's Perspective", en R. Dorfman y N.S. Dorfman (eds.), Economics of the Environment, New York, WW Norton \& Company.

(1974), "La economía de los recursos o los recursos de la economía”, The American Economic Review, vol. 64, núm. 2, Documentos y Actas de la Ochenta y Sexta Reunión Anual de la Asociación Económica Americana.

TN (2016), "Confirman que Barrick Gold contaminó con cianuro 5 ríos en San Juan", nota periodística, 23 de febrero. Recuperada de <https:// tn.com.ar/sociedad/confirman-que-barrick-gold-contamino-con-cianuro5-rios-en-san-juan_654592>

unOps (2016), "Estudio sobre la calidad de los cuerpos de agua en el área de influencia de mina Veladero posterior al incidente ambiental del 13/09/15" (Informe ECCA Veladero). Resumen Ejecutivo. Naciones Unidas. Recuperado de <http://auditoriaambiental.org/wp-content/uploads/2016/05/ Resumen-ejecutivo-ECCA_08-04-2016.pdf> 